EPJ Web of Conferences 52, 04009 (2013)

DOI: $10.1051 /$ epjconf/20135204009

(C) Owned by the authors, published by EDP Sciences, 2013

\title{
First results of the SPHERE experiment
}

\author{
Sergey Shaulov ${ }^{1, a}$ \\ ${ }^{1}$ Lebedev Physical Institute of the Russian Academy of Sciences, Russia
}

\begin{abstract}
First results of the balloon-borne experiment SPHERE are presented. The primary spectrum in the energy range $10^{16}-5 \cdot 10^{17} \mathrm{eV}$ is compared with data of other experiments. The primary energies were reconstructed using characteristics of the VavilovCherenkov radiation from extensive air showers, reflected from a snow surface.
\end{abstract}

Slides

The slides of the talk can be found on the website of the symposium ISVHECRI 2012: https://indico.desy.de/conferenceOtherViews.py?view=standard\& $\operatorname{confId}=4594$

a ser101@inbox.ru 